\title{
AIRPLANE MATERIALS COMPATIBILITY WITH BLENDS OF FOSSIL KEROSENE JET A1 WITH BIOKEROSENES FROM BABASSU, PALM KERNEL AND COCONUT OILS
}

\author{
AL-LAL A. ${ }^{1,2}$ \\ LLAMAS A. ${ }^{1}$ \\ BOLONIO D. ${ }^{1}$ \\ SANZ-PÉREZ F. ${ }^{2}$ \\ LAPUERTA M. ${ }^{3}$ \\ CANOIRA L. ${ }^{1}$
}

\author{
${ }^{1}$ Department of Chemical Engineering \& Fuels \\ ETS Ingenieros de Minas, Universidad Politécnica de Madrid \\ Ríos Rosas 21, 28003-Madrid, Spain \\ ${ }^{2}$ Fuels and Petrochemistry Laboratory, Gómez-Pardo Foundation \\ Technogetafe Scientific Park, Eric Kandel 1,28906-Getafe, Spain \\ ${ }^{3}$ Grupo de Combustibles y Motores, ETS Ingenieros Industriales \\ Universidad de Castilla La Mancha, Avda. Camilo José Cela s/n \\ 13071-Ciudad Real, Spain
}

Received: 30/01/2014

Accepted: 01/04/2014

Available online: 29/05/2014 *to whom all correspondence should be addressed: e-mail: david.bolonio@upm.es

\section{ABSTRACT}

Currently there is a big interest to increase the sources of alternative fuels for aviation to get a reduction of their carbon footprint and the deep energetic dependence from fossil fuels of different countries. Although there are studies about how to produce this alternative fuel and how to accomplish the standards for a good performance in the aircraft turbines, there are no studies about how these fuels could affect the different materials of airplanes. In this context this work describes the compatibility of biokerosene blends of coconut, babassu and palm kernel with commercial Jet A-1 testing airplane polymeric materials, metals and composites. As a conclusion, all material samples show a good compatibility with the fuel blends tested.

Keywords: Biokerosene, compatibility, airplane, materials

\section{Introduction}

In the last few decades the global aviation industry has experienced a tremendous growth and development that, according to the forecast, will continue at the same or increasing rate in the forthcoming years. Due to this situation the aviation companies are facing some problems that argue in favour of biofuels: the rising cost of traditional fuel and its price volatility, the energetic dependence of many countries and the environmental concerns. In ten years the price of the jet fuel has increased a $352.4 \%$ from October 2003 (0.82 USD/gallon) to October 2013 (2.89 USD/gallon) reaching a peak in July 2008 of 3.89 USD/gallon (Index Mundi, 2014). The changing fuel prices make airline operators very difficult to plan and budget for long-term operating expenses. Moreover the environmental impact of the aviation sector represents approximately $3 \%$ of global $\mathrm{CO}_{2}$ emitted to atmosphere (Howitt et al., 2011). Every year 18000 planes consume 200 million tons of jet fuel, corresponding to around $5 \%$ of world petroleum consumption (Aviation Civile, 2010). In addition airplanes emissions have a great global impact due to the altitude of emission. Carbon dioxide, water, nitrogen oxides, carbon monoxide, hydrocarbons, sulphur oxides, sulfates, and airborne particles have different effects depending on the altitude of emission. At ground level, aircraft emissions at large airports are important sources of local and regional air pollution including hydrocarbons and fine particulate matter which can increase the people's risk of heart disease and asthma. At flight altitude these emissions have impacts in both 
tropospheric chemistry and global warming (Llamas et al., 2013). The emissions of an airplane turbine are the results of the combustion process of the jet fuel, and it is here where the use of more efficient fuels with less carbon content could diminish these emissions without the need to modify substantially these turbines.

Trying to face this situation, the aviation companies are considering seriously the use of alternative jet fuels to reduce greenhouse gas emissions and to lower their costs (Bows et al., 2007). Aviation companies prefer the so called "drop-in" fuels that could be used without substantial changes in the turbines. There are currently three main research strategies for alternative aviation fuels as following: Fischer-Tropsch - synthetic paraffin kerosene (FT-SPK), hydroprocessed esters and fatty acids (HEFA) and finally fatty acid esters (FAEs).

Fischer-Tropsch fuel is synthesized from coal (CTL), biomass (BTL) or natural gas (GTL). The final fuel is mainly a mixture of $n$-alkanes, isoalkanes and cyclic alkanes which has very similar properties to those of the Jet A or Jet A-1 (Kinder and Rahmes, 2007). Although the use of F-T fuels could address the security of supply, it does little to contribute towards any positive environmental impact as life-cycle studies show (Steele et al., 2012; Marano and Ciferno, 2002).

In the hydroprocessed renewable oil process, vegetable oils and fats are reacted with hydrogen gas and converted to jet fuel thanks to a catalytic hydrodeoxygenation and subsequent selective cracking and isomerization of tryglycerides. It has been reported lifecycle greenhouse gas (GHG) emissions $60 \%$ lower than petroleum-based fuels (Pearlson et al., 2013). However, nowadays changes must be done to reach their economic viability.

The use of both FT-SPK and HEFA in aviation has been approved for blends of up to $50 \%$ according to the standard ASTM D-7566 and the standard DEF-STAN 91-91.

This work is based in the third strategy: fatty acid esters (FAEs), derived from the transesterification of triglycerides in vegetable, animal or waste oils. The literature on the production and use of FAEs for the aviation sector is still scarce. The main advantages are the simple and low cost technology of the process and the reduction of life-cycle $\mathrm{CO}_{2}$ emissions (Hong et al., 2013). Nevertheless to be accepted for blends with commercial Jet A-1 these fuels must fulfil a set of extraordinarily sensible properties to guarantee the safety of passengers and planes during the flights.

While some authors have studied the properties of alternative aviation fuels related to their performance in a turbine (heating value, freezing point, oxidation) (Dunn, 2001; Korres et al., 2008; Hileman et al., 2010) there are no studies related to the effect of this fuel in contact with airplane materials. The design both the engine and the fuel system includes many materials of different composition whose compatibility with the fuel they are contacted with is indispensable to guarantee the safety at all times.

The materials should be able to resist great efforts and charges that the airplane suffers during the flight. These materials affect the airplane weight, the aerodynamic shapes and the structural resistance to support the compressed air in the airplane inside. In this latter case, for a correct pressurization, the airplane fuselage should be completely sealed, and to this aim, three construction methods are used:

- The sealing of the joints with soft materials that avoid the pass of humidity.

- The use of gum in all the holes of the pressurized walls.

- The use of inflatable pneumatical joints in the frame of the great holes like doors.

The four great groups of aerospace materials are:

- Iron alloys.

- Lightweight aluminium, titanium of magnesium alloys.

- Composite materials generally made of carbon fibre in an epoxy resin matrix.

- Auxiliary materials (gums, plastics, canvas). 
The charges are also a fundamental element to take into account in an airplane. The traction or pushing charges supported and generated by the propulsion system should be taken into account when electing the construction materials for an airplane.

The use of composites allows the construction of lighter and more efficient airplanes, and thus less polluting. Moreover, the development of new production techniques has approached the construction costs of these composites to that of aluminium alloys. The composites used in airplanes are of the "composite fibres" type, formed by continuous fibres in sheets, united by a resin or plastic matrix. The fibres provide the structural properties, while the matrix binds the fibres in a structural unit. For aeronautical application the fibres used are carbon fibres, aramid (Kevlar), boron and glass fibres, and the main matrix material is the epoxy resin. The main reason to use composites in airplanes is their high ratio effort/weight and resistance/weight, compared to the traditional aluminium alloys. The weight saving is around $25 \%$ compared to metals.

The aim of this paper is to study the compatibility of three types of materials present in the modern airplanes with blends of biokerosene based in fatty acid methyl esters (FAME) and Jet-A1, and whose production and properties have been described previously (Llamas et al., 2012a). Polymer materials have been tested for traction, resistance, hardness, and mass and dimensional variations. Metals (silver and copper) have been tested for corrosion and the blends of jet fuel have been tested, before and after the immersion of the composites, for acidity, density, viscosity, colour and Fourier transformed infrared absorption (FTIR) to evaluate possible compositional changes.

\section{Materials}

\subsection{Biokerosene}

The raw materials to produce biokerosene are coconut, babassu and palm kernel oils. All these three oils are composed mainly of saturated fatty acids with short chain length. These ester profiles lead to better properties especially the cold performance as it was shown in previous works (Llamas et al., 2012a; Llamas et al., 2012b).

Refined coconut oil was purchased from Acros Organics (CAS No. 8001-31-8), babassu oil and crude palm kernel oil were supplied by Combustibles Ecológicos Biotel SL and Kerosene Jet A-1 was obtained from the Spanish Company Logística de Hidrocarburos (CLH).

Biokerosenes were produced via basic transesterification process following the experimental procedure previously described in the literature. Then, to obtain the adequate kerosene fraction of the FAMEs a vacuum distillation process was carried out (Llamas et al., 2012a; Llamas et al., 2012b).

The three biokerosenes were blended with commercial Jet $A-1$ in a ratio $80 \%(v / v)$ Jet $A-1,20 \%(v / v)$ biokerosene obtaining in this way three blends: coconut biokerosene blend (CBK20), babassu biokerosene blend (BBK20) and palm kernel biokerosene blend (PBK20).

\subsection{Aircraft materials}

The first group of materials tested in this work were polymers which form an important part of the fuel system of the plane and are under different states of load, pressure and temperature during their useful life. They are used in the deposits, tanks, valves, joints and other components of the airplane fuel system. All polymers were purchased from Grupo de Empresas y Talleres (Madrid). Tested polymers are thermoplastics as polyvinyl chloride (PVC), polypropylene (PP) and polyethylene (PE) and elastomeric polymers as styrene butadiene rubber (SBR) and VITON which is a trademark patented by Dupont company.

To be able to carry out the study, the samples were made according to the standard of the tensile test for polymers ASTM D638 (Figure 1). They were built with a manual press, model 6051000 CEAST.

The second group of tested materials are metals: silver and copper, both used in the design of the engine. These materials are thoroughly used to fight corrosion in the components of the fuel system. In 
aviation the copper oxide is mainly used to form an anticorrosive layer on the underlying layers of metal. It improves their properties at low temperatures, making it suitable for cryogenic applications.

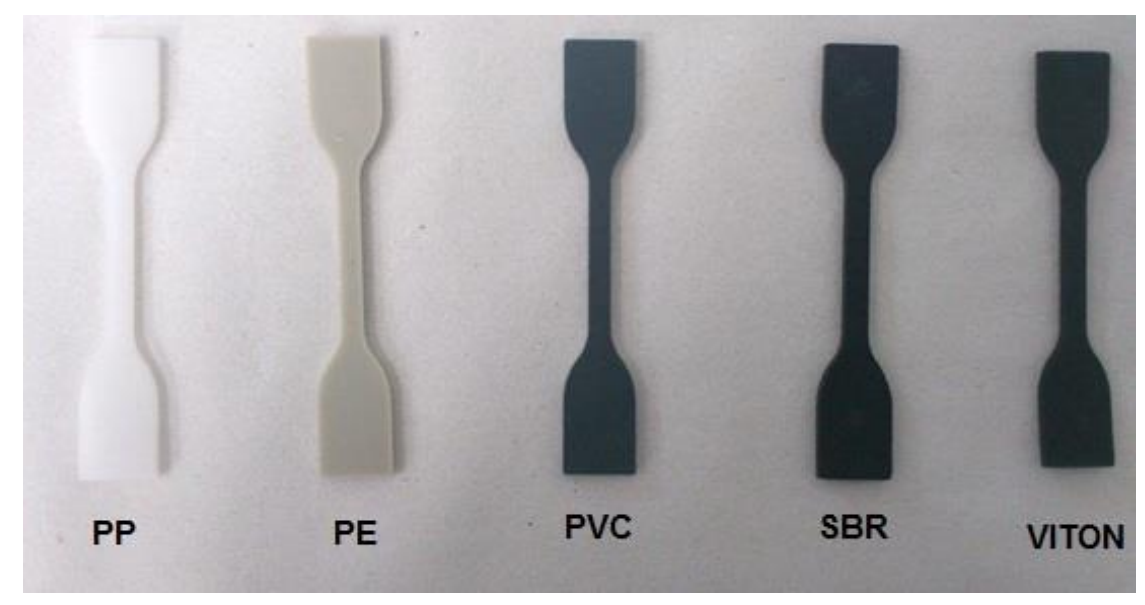

Figure 1. Samples of polymers.

The compatibility test with metals is based on the determination of the corrosion caused by the fuel in contact with the metals. Aviation fuel contains potential corrosive compounds that are limited by the specifications, like mercaptans $(\max .0 .002 \%(\mathrm{~m} / \mathrm{m})$ in Jet $A-1)$, or organic acids. Also traces of compounds such as sodium, potassium and other alkaline metals present in the fuel can cause corrosion in the turbine engine. Trying to face the problem of corrosion the aircraft companies use aluminium to build the fuel deposits and steel covered by copper and silver to create a protection layer. These two metals have been tested for corrosion with our biojet samples.

The third and final group of materials tested were some samples of composite materials. Composites have good tensile strength and resistance to compression, making them suitable for use in aircraft part manufacture. The tensile strength of the material comes from its fibrous nature. The good resistance to compression can be attributed to the adhesive and stiffness properties of the base matrix system. It is the role of the resin to maintain the fibres as straight columns and to prevent them from buckling. In particular in this work ribs and wings from the airplane provided by Airbus Company were tested. These samples include a main part composed of carbon fibre with a titanium screw electrically isolated, yellow paint in the surface and phenylene polysulphide in the joints to seal the structure (Figure 2).
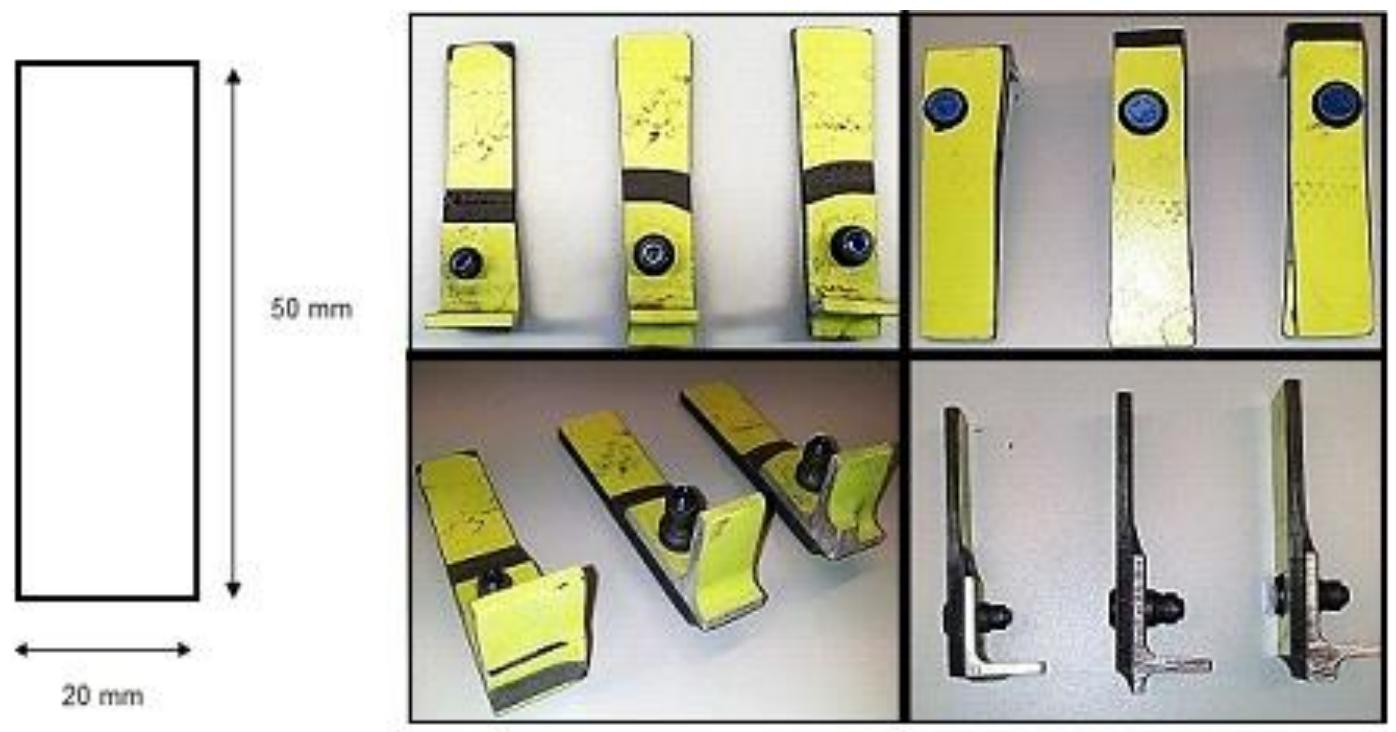

Figure 2. Samples of composites. 


\section{Methods}

Different tests were done depending on the group of materials:

\subsection{Polymers}

Each of the compatibility tests with the polymeric materials was performed with a full immersion of the five samples in the fuels studied. The tests were conducted in order to assess the degree of degradation of the polymer, by determining the tensile properties, toughness, discoloration, and variation of the linear dimensions of the specimens. These tests were carried out in sealed vessels, subjected to a temperature of $35{ }^{\circ} \mathrm{C}$, for a period of 28 days (672 hours) in a furnace EN 400 from NÜVE. The tests, standards and the equipment need for each test are shown in Table 1.

\subsection{Metals}

The compatibility test with metals is based on the determination of the corrosion caused by the fuel in contact with the metals. Trying to face the problem of corrosion the aircraft companies use aluminium to build the fuel deposits and steel covered by copper and silver to create a protection layer.

- Silver strip corrosion test: The test is based on the standard IP 227. A silver strip is completely immersed in a volume of fuel for 4 hours at a temperature of $50{ }^{\circ} \mathrm{C}$. Then the strip is compared with some reference strips (ASTM D7671).

- Copper strip corrosion test: Similar to the previous test, the copper strips are immersed in a volume of fuel for 4 hours at a temperature of $50^{\circ} \mathrm{C}$ and compared with some reference strips in standard ASTM D130.

\subsection{Composites}

The compatibility with these materials was studied through a different approach. Instead of measuring the changes in the composites caused by the immersion in the fuel samples, the effect of the contact with the composites was measured on the fuel. The samples were immersed in the different blends for 90 days ( 2160 hours) at a temperature of $50{ }^{\circ} \mathrm{C}$ using a furnace EN 400 NÜVE. The fuel degradation was measured by analysing the oxidation and nitration bands obtained after undergoing compatibility tests measured with FTIR. Four samples were taken, the first one at the beginning of the test and the others every 30 days. The rest of the characteristics measured before and after the immersion are summarized in Table 1.

Table 1. Polymer tests, metal tests and characteristics tested in the composites after the contact with the fuel blends.

\begin{tabular}{cccc}
\hline Test & Standard & Equipment & Experimental error \\
\hline Tensile test & UNE 53510 & INSTRON 3360 & $\begin{array}{c} \pm 6.22 \% \text { (stress) } \\
\pm 7.12 \% \text { (strain) }\end{array}$ \\
\hline Hardness test & ASTM D2240 & $\begin{array}{c}\text { Durometer Shore A, model } \\
\text { Macro-IRHD-2 (Hildebrand) }\end{array}$ & $\pm 3.11 \%$ \\
\hline $\begin{array}{c}\text { Mass and size } \\
\text { variation }\end{array}$ & - & $\begin{array}{c}\text { Balance, model AE 200 } \\
\text { (Mettler) and a Vernier caliper }\end{array}$ & $\begin{array}{c} \pm 0.0002 \mathrm{~g} \\
\pm 0.01 \mathrm{~mm}\end{array}$ \\
\hline $\begin{array}{c}\text { Silver strip corrosion } \\
\text { test }\end{array}$ & ASTM D7671 & $\begin{array}{c}\text { Thermostatic bath (Bretteville } \\
\text { laboratory) }\end{array}$ & - \\
\hline $\begin{array}{c}\text { Copper strip corrosion } \\
\text { test }\end{array}$ & ASTM D130 & $\begin{array}{c}\text { Thermostatic bath (Bretteville } \\
\text { laboratory) }\end{array}$ & - \\
\hline Acidity & UNE-EN ISO 660 & - & $\pm 0.02 \mathrm{mg} \mathrm{KOH} \mathrm{g}^{-1}$ \\
\hline Density & ASTM D4052 & $\begin{array}{c}\text { Densimeter DMA 48 (Anton } \\
\text { Paar GmbH) }\end{array}$ & $\pm 0.3 \mathrm{~kg} \mathrm{~m}^{-3}$ \\
\hline $\begin{array}{c}\text { Kinematic viscosity at } \\
\text { 20 }{ }^{\circ} \mathrm{C}\end{array}$ & ASTM D445 & $\begin{array}{c}\text { Ostwald-Cannon-Fenske } \\
\text { viscometer }\end{array}$ & $\pm 0.20 \%$ \\
\hline Colour measurement & DEF STAN 91-91 & Colorimeter AF 650 (Lovibond) & $\pm 0.5 \mathrm{u.c.}$ \\
\hline
\end{tabular}




\section{Results and discussion}

\subsection{Polymers}

\subsubsection{Tensile test}

Table 2 specifies the differences found between the polymer samples tested with Jet A-1 and BBK20 and another sample without contact with the fuel.

Table 2. Results of the tensile test.

\begin{tabular}{|c|c|c|c|c|}
\hline \multirow{3}{*}{$\begin{array}{l}\text { Standard UNE } 53510 \\
\text { PVC }\end{array}$} & \multicolumn{2}{|c|}{ Jet $A-1$} & \multicolumn{2}{|c|}{ BBK20 } \\
\hline & \multicolumn{2}{|c|}{ Difference } & \multicolumn{2}{|c|}{ Difference } \\
\hline & $\Delta$ & $\%$ & $\Delta$ & $\%$ \\
\hline Stress at maximum load (MPa) & 12.78 & 2.80 & -16.50 & -3.61 \\
\hline Strain at maximum load (\%) & 1.68 & 50.60 & 1.68 & 50.60 \\
\hline \multirow[t]{2}{*}{ PP } & \multicolumn{2}{|c|}{ Difference } & \multicolumn{2}{|c|}{ Difference } \\
\hline & $\Delta$ & $\%$ & $\Delta$ & $\%$ \\
\hline Stress at maximum load (MPa) & -31.20 & -9.63 & -40.76 & -12.58 \\
\hline Strain at maximum load (\%) & 0.84 & 12.54 & 1.67 & 25.08 \\
\hline \multirow[t]{2}{*}{ PE } & \multicolumn{2}{|c|}{ Difference } & \multicolumn{2}{|c|}{ Difference } \\
\hline & $\Delta$ & $\%$ & $\Delta$ & $\%$ \\
\hline Stress at maximum load (MPa) & -75.32 & -21.01 & -95.29 & -26.58 \\
\hline Strain at maximum load (\%) & 3.34 & 50.15 & 6.67 & 100.15 \\
\hline \multirow[t]{2}{*}{ SBR } & \multicolumn{2}{|c|}{ Difference } & \multicolumn{2}{|c|}{ Difference } \\
\hline & $\Delta$ & $\%$ & $\Delta$ & $\%$ \\
\hline Stress at maximum load (MPa) & -1.16 & -12.75 & -0.44 & -4.86 \\
\hline Strain at maximum load (\%) & -18.34 & -8.94 & -15.00 & -7.32 \\
\hline \multirow[t]{2}{*}{ VITON } & \multicolumn{2}{|c|}{ Difference } & \multicolumn{2}{|c|}{ Difference } \\
\hline & $\Delta$ & $\%$ & $\Delta$ & $\%$ \\
\hline Stress at maximum load (MPa) & 0.46 & 11.39 & -0.02 & -0.50 \\
\hline Strain at maximum load (\%) & -35.01 & -42.86 & -26.67 & -32.66 \\
\hline
\end{tabular}

According to the tensile test three important conclusions can be inferred:

- The behaviour of the samples tested with Jet A-1 or BBK20 is very similar.

- There are two different behaviours between the two groups of polymers: The thermoplastic polymers (PVC, PP and PE) after the contact with the fuel tend to increase the strain at maximum load and the elastomeric polymers (SBR and VITON) which have the opposite effect. Elastomers allow the inclusion of fuel molecules between the polymeric chains lowering the strain but thermoplastics do not allow it.

- The most affected parameter is the deformation or strain. For example in the case of VITON it was reduced nearly $43 \%$ while the PVC sample reached an increase of $50.60 \%$. Although VITON has been designed to resist most of chemicals, the fuel molecules affect it greatly reducing its strain, whereas the chlorine presence in PVC enhances this property after the fuel immersion.

\subsubsection{Hardness test}

Table 3 shows the results of the hardness test. 
Table 3. Results of the hardness test.

\begin{tabular}{|c|c|c|c|c|c|c|c|c|}
\hline \multirow[t]{2}{*}{ PVC } & \multicolumn{2}{|c|}{ Jet $A-1$} & \multicolumn{2}{|c|}{ Difference } & \multicolumn{2}{|c|}{ BBK20 } & \multicolumn{2}{|c|}{ Difference } \\
\hline & Before & After & $\Delta$ & $\%$ & Before & After & $\Delta$ & $\%$ \\
\hline Hardness & 98.16 & 98.22 & 0.06 & 0.06 & 98.16 & 98.42 & 0.26 & 0.26 \\
\hline \multirow[t]{2}{*}{ PP } & \multicolumn{2}{|c|}{ Jet $A-1$} & \multicolumn{2}{|c|}{ Difference } & \multicolumn{2}{|c|}{ BBK20 } & \multicolumn{2}{|c|}{ Difference } \\
\hline & Before & After & $\Delta$ & $\%$ & Before & After & $\Delta$ & $\%$ \\
\hline Hardness & 98.06 & 95.57 & -2.49 & -2.54 & 98.06 & 98.58 & 0.52 & 0.53 \\
\hline \multirow[t]{2}{*}{ PE } & \multicolumn{2}{|c|}{ Jet $A-1$} & \multicolumn{2}{|c|}{ Difference } & \multicolumn{2}{|c|}{ BBK20 } & \multicolumn{2}{|c|}{ Difference } \\
\hline & Before & After & $\Delta$ & $\%$ & Before & After & $\Delta$ & $\%$ \\
\hline Hardness & 98.52 & 98.54 & 0.02 & 0.02 & 98.52 & 97.76 & -0.76 & -0.77 \\
\hline \multirow[t]{2}{*}{ SBR } & \multicolumn{2}{|c|}{ Jet $A-1$} & \multicolumn{2}{|c|}{ Difference } & \multicolumn{2}{|c|}{ BBK20 } & \multicolumn{2}{|c|}{ Difference } \\
\hline & Before & After & $\Delta$ & $\%$ & Before & After & $\Delta$ & $\%$ \\
\hline Hardness & 78.76 & 78.91 & 0.15 & 0.19 & 78.76 & 77.54 & -1.22 & -1.55 \\
\hline \multirow[t]{2}{*}{ VITON } & \multicolumn{2}{|c|}{ Jet $A-1$} & \multicolumn{2}{|c|}{ Difference } & \multicolumn{2}{|c|}{ BBK20 } & \multicolumn{2}{|c|}{ Difference } \\
\hline & Before & After & $\Delta$ & $\%$ & Before & After & $\Delta$ & $\%$ \\
\hline Hardness & 81.31 & 90.16 & 8.85 & 10.88 & 81.31 & 82.56 & 1.25 & 1.54 \\
\hline
\end{tabular}

The following effects can be observed:

- The thermoplastic polymers show higher hardness that the elastomeric polymers.

- While samples tested with BBK20 show a change always lesser than $2 \%$, samples of PP and VITON tested with Jet A-1 have greater changes. The biggest change is found in the case of VITON, resulting in an increase of hardness of $10.88 \%$.

- Although the performance of the samples show no important changes in the hardness, comparing the behaviour between samples tested with Jet A-1 and samples tested with BBK20 remarkable differences could be observed. In fact in three cases the behaviour is the opposite. PP has a chemical structure based in hydrocarbons like Jet A-1 but the ester structure of BBK20 affects it in a different way. The PP sample tested with Jet A-1 reduces its hardness while the one tested with BBK20 increases it. In the case of PE and SBR samples, the opposite happens. An increase of the hardness is observed in the test with Jet A-1 while the samples in BBK20 reduce its hardness.

\subsubsection{Dimensional linear variation}

Table 4. Results of the dimensional linear variation test.

\begin{tabular}{lccccccccc}
\hline SBR & \multicolumn{2}{c}{ Jet A-1 } & \multicolumn{2}{c}{ Difference } & \multicolumn{2}{c}{ BBK20 } & \multicolumn{2}{c}{ Difference } \\
& Before & After & $\Delta$ & $\%$ & Before & After & $\Delta$ & $\%$ \\
$\mathrm{~L}^{1}$ & 74.46 & 74.32 & -0.14 & -0.19 & 74.62 & 74.86 & 0.24 & 0.32 \\
$\mathrm{HW}^{2}$ & 12.22 & 12.12 & -0.10 & -0.82 & 12.17 & 12.18 & 0.01 & 0.08 \\
$\mathrm{LW}^{3}$ & 3.85 & 3.72 & -0.14 & -3.51 & 3.79 & 3.72 & -0.08 & -1.98 \\
$\mathrm{~T}^{4}$ & 1.83 & 1.83 & 0.00 & 0.00 & 1.91 & 1.95 & 0.04 & 2.09 \\
VITON & \multicolumn{2}{c}{ Jet A-1 } & \multicolumn{4}{c}{ Difference } & BBK20 & Difference \\
\multicolumn{1}{l}{} & Before & After & $\Delta$ & $\%$ & Before & After & $\Delta$ & $\%$ \\
$\mathrm{H}$ & 74.67 & 82.59 & 7.93 & 10.61 & 74.58 & 84.63 & 10.05 & 13.47 \\
$\mathrm{LW}$ & 12.29 & 13.70 & 1.41 & 11.47 & 12.39 & 13.94 & 1.55 & 12.51 \\
$\mathrm{~T}$ & 3.81 & 4.13 & 0.32 & 8.41 & 3.83 & 3.96 & 0.13 & 3.26 \\
\hline
\end{tabular}

$1 \mathrm{~L}$, Length, $2 \mathrm{HW}$, Higher Width, 3 LW, Lower Width, 4 T, Thickness 
In Table 4 the thermoplastic polymers PVC, PP and PE are not included because they do not show any change in size during the tests. The difference between SBR and VITON is remarkable. The highest values correspond to VITON, which reached an $11.47 \%$ in the higher width with the Jet A-1 test. Moreover it should be noted the dimensional reduction that occurs in the test with SBR in Jet A-1, while the testing with VITON increases both in length and thickness. In relation to the behaviour between samples tested with Jet A-1 and BBK20 no significant changes could be found.

\subsubsection{Mass variation}

In Table 5 the thermoplastic polymers PVC, PP and PE are not included because they do not show any mass variation during the tests.

Table 5. Results of the mass variation test.

\begin{tabular}{lccccccccc}
\hline \multirow{2}{*}{ SBR } & \multicolumn{2}{c}{ Jet A-1 } & \multicolumn{2}{c}{ Difference } & \multicolumn{2}{c}{ BBK20 } & \multicolumn{2}{c}{ Difference } \\
\cline { 2 - 10 } & Before & After & $\Delta$ & $\%$ & Before & After & $\Delta$ & $\%$ \\
\hline Mass & 2.26 & 2.12 & -0.04 & -1.89 & 2,33 & 2.34 & 0.01 & 0.56 \\
\hline VITON & \multicolumn{2}{c}{ Jet A-1 } & \multicolumn{2}{c}{ Difference } & \multicolumn{2}{c}{ BBK20 } & \multicolumn{2}{c}{ Difference } \\
\cline { 2 - 9 } & Before & After & $\Delta$ & $\%$ & Before & After & $\Delta$ & $\%$ \\
\hline Mass & 2.00 & 2.36 & 0.36 & 18.16 & 2.01 & 2.53 & 0.52 & 25.82 \\
\hline
\end{tabular}

Related to the elastomeric polymers, a major mass increase is observed during the tests with VITON and Jet A-1 or BBK20 reaching $18.16 \%$ and $25.82 \%$ respectively. This happens by absorption of fuel during the test, higher in the case of BBK20.

\subsection{Metals}

In the silver strip corrosion test every sample was given a level of " 0 " according to the scale of the standard ASTM D7671 while in the copper strip corrosion test all the samples showed a level of "1a" according to the standard ASTM D130.

In accordance with the results obtained in the tests it can be said that both metals, silver and copper, showed a perfect compatibility with the fuel BBK20.

\subsection{Composites}

The results of the acidity, density and viscosity tests are shown in Table 6.

Table 6. Results of the acidity, density and viscosity tests.

\begin{tabular}{lcccc}
\hline \multirow{2}{*}{ Acidity } & Before & \multicolumn{2}{c}{ After } & \multicolumn{2}{c}{ Difference } \\
\cline { 2 - 5 } & TAN $\left(\mathrm{mg} \mathrm{KOH} \mathrm{g}^{-1}\right)$ & TAN $\left(\mathrm{mg} \mathrm{KOH} \mathrm{g}^{-1}\right)$ & \multicolumn{2}{c}{$\Delta$} \\
\hline Jet A-1 & 0.01 & 0.06 & 0.04 \\
\hline CBK20 & 0.02 & 0 & -0.02 \\
\hline BBK20 & 0.03 & 0 & -0.03 \\
\hline PBK20 & 0.01 & 0.05 & \multicolumn{2}{c}{0.04} \\
\hline Density & Before & After & \multicolumn{2}{c}{ Difference } \\
\hline & Density $\left(\mathrm{kg} \mathrm{m}^{-3}\right)$ & Density $\left(\mathrm{kg} \mathrm{m}^{-3}\right)$ & $\Delta$ & $\%$ \\
\hline Jet A-1 & 788.4 & 788.5 & 0.1 & 0.01 \\
\hline CBK20 & 812 & 814.5 & 2.5 & 0.31 \\
\hline BBK20 & 814.9 & 814.7 & 0.2 & -0.02 \\
\hline PBK20 & 811.8 & 814.8 & 3 & 0.37 \\
\hline Kinematic viscosity at $\mathbf{- 2 0}^{\circ} \mathrm{C}$ & Before & After & Difference \\
\cline { 2 - 5 } & Viscosity $\left(\mathrm{mm}^{2} \mathrm{~s}^{-1}\right)$ & Viscosity $\left(\mathrm{mm}^{2} \mathrm{~s}^{-1}\right)$ & $\Delta$ & $\%$ \\
\hline Jet A-1 & 1.03 & 1.07 & 0.04 & 4.01 \\
\hline CBK20 & 1.19 & 1.38 & 0.19 & 15.75 \\
\hline BBK20 & 1.32 & 1.32 & 0.002 & -0.13 \\
\hline PBK20 & 1.27 & 1.39 & 0.12 & 9.11 \\
\hline
\end{tabular}


No sample exceeds the maximum acidity given by the standard ASTM D1665 which is $0.1 \mathrm{mg} \mathrm{KOH} \mathrm{g}^{-1}$. It is remarkable that the acidity even decreases when the composite is submerged in CBK20 and BBK20.

The density is also in the range of the standard which is $775-840 \mathrm{~kg} \mathrm{~m}^{-3}$ and all the samples have more density than the Jet A-1. This is usually the case with FAMEs.

Values of kinematic viscosity show slight changes after the test and all of them are far below the maximum established by standard ASTM D1655 $\left(8 \mathrm{~mm}^{2} \mathrm{~s}^{-1}\right)$.

As for the colour test, the results show no change from the initial values, dismissing the possibility of fuel degradation during testing.

In addition, all samples meet the standard for aviation fuel DEF STAN 91-91, which requires the colour of kerosene used in aviation to be clear and colourless.

Through FTIR test the oxidation and nitration bands were measured to study the degradation of the composites, but spectra did not show any trace of oxidation compounds.

\section{Conclusion}

After studying the results, the first important conclusion is that there is no different performance of the materials using Jet A-1 than using the blends studied. In addition there is a clear distinction between how the polymer responds to a test depending if it is an elastomer or a thermoplastic polymer. Moreover VITON is the material which showed the highest change in its properties once it is mixed with the fuel. Regarding the metals, both silver and copper show no corrosion after the tests and all the tests done with the composites have results according to their standard.

Therefore all the biokerosene samples evaluated show a good compatibility with the used materials, polymers, metals or composites.

\section{Acknowledgments}

The authors would like to thank the help of the Fuels and Petrochemistry Laboratory in Technogetafe and the technical staff of the School of Mines Laboratory. Also to mention the contribution of the Airbus Company that has provided the composite materials of an airplane necessary for the tests, and of the JEMAC SL that cut the composite samples for the immersion tests.

\section{References}

ASTM Standard D7566, "Standard specification for aviation turbine fuel containing synthesized hydrocarbons". ASTM International: West Conshohocken, PA, 2013.

Bows A., Anderson K., and Peeters P. (2007), Technology, scenarios and uncertainties. Working paper, Tyndall Centre Manchester, The University of Manchester, available at http://tyndall. web. man. ac. uk/publications/Technology\% 20Scenarios\% 20and\% 20Uncertainties\% 202007. pdf.

Constant, Olivier (2010). Carburants alternatifs: Les efforts s'intensifient. Aviation Civile, 355, 10-15.

Dunn R.O. (2001), Alternative jet fuels from vegetable oils, Transactions of the ASAE, 44(6), 1751-1757.

Hileman J.I., Donohoo P.E. and Stratton R.W. (2010), Energy content and alternative jet fuel viability, Journal of Propulsion and Power, 26(6), 1184-1196.

Hong T.D., Soerawidjaja T.H., Reksowardojo I.K., Fujita O., Duniani Z. and Pham M.X. (2013), A study on developing aviation biofuel for the Tropics: Production process-Experimental and theoretical evaluation of their blends with fossil kerosene, Chemical Engineering and Processing: Process Intensification, 74, 124-130.

Howitt O.J., Carruthers M.A., Smith I.J. and Rodger C.J. (2011), Carbon dioxide emissions from international air freight, Atmospheric Environment, 45(39), 7036-7045.

Index Mundi, www.indexmundi.com, accessed January 7th, 2014.

Kinder JD. and Rahmes T. (2007), Evaluation of Bio-Derived Synthetic Paraffinic Kerosenes (Bio-SPK), The Boeing Company. 
Korres D.M., Karonis D., Lois E., Linck M.B. and Gupta A.K. (2008), Aviation fuel JP-5 and biodiesel on a diesel engine, Fuel, 87(1), 70-78.

Llamas A., Al-Lal A.M., Hernandez M., Lapuerta M. and Canoira L. (2012b), Biokerosene from babassu and camelina oils: Production and properties of their blends with fossil kerosene, Energy and Fuels, 26(9), 5968-5976.

Llamas A., García-Martínez M.J., Al-Lal A.M., Canoira L. and Lapuerta M. (2012a), Biokerosene from coconut and palm kernel oils: Production and properties of their blends with fossil kerosene, Fuel, 102, 483-490.

Llamas A., Lapuerta M., Al-Lal A.M. and Canoira L. (2013), Oxygen Extended Sooting Index of FAME blends with aviation kerosene, Energy and Fuels, 27(11), 6815-6822.

Marano J.J. and Ciferno J.P. (2001), Life-cycle greenhouse-gas emissions inventory for Fischer-Tropsch fuels. Report Prepared for the US Department of Energy, Energy and Environmental Solution, LLC, Gaithersburg, MD, USA.

Pearlson M., Wollersheim C. and Hileman J. (2013), A techno-economic review of hydroprocessed renewable esters and fatty acids for jet fuel production, Biofuels, Bioproducts and Biorefining, 7(1), 89-96.

Stan D.E.F. 91-91: Turbine Fuel, Aviation Kerosine Type, Jet A-1 NATO Code: F-35, Joint Service Designation: AVTUR. Ministry of Defence.

Steele P., Pearce B., Ríos A., Nash P., Massat F., Young N and Scott T. (2011), Powering the Future of Flight. Proceedings of the World Biofuels Markets, 22-24. 